\title{
CONVERGENCE THEOREMS BY HYBRID PROJECTION METHODS FOR LIPSCHITZ-CONTINUOUS MONOTONE MAPPINGS AND A COUNTABLE FAMILY OF NONEXPANSIVE MAPPINGS
}

\author{
SOMYOT PLUBTIENG \\ Department of Mathematics, Faculty of Science \\ Naresuan University, Pitsanulok 65000, Thailand \\ E-mail: somyotp@nu.ac.th \\ POOM KUMAM \\ Department of Mathematics, Faculty of Science \\ King Mongkut's University of Technology Thonburi (KMUTT) \\ Bangkok 10140, Thailand \\ E-mail: poom.kum@kmutt.ac.th
}

\begin{abstract}
In this paper, we introduce two iterative schemes for finding a common element of the set of a common fixed points of a countable family of nonexpansive mappings and the set of solutions of the variational inequality problem for a monotone, Lipschitz-continuous mapping in a Hilbert space by using the hybrid projection methods in the mathematical programming. Then we prove strong convergence theorems by the hybrid projection methods for a monotone, Lipschitz-continuous mapping and a countable family of nonexpansive mappings. Moreover, we apply our result to the problem for finding a common fixed point of two mappings, such that one of these mappings is nonexpansive and the other is taken from the more general class of Lipschitz pseudocontractive mappings. Our results extend and improve the results of Nadezhkina and Takahashi [SIAM J. Optim. 16 (2006), 1230-1241], Zeng and Yao [Taiwanese J. Math. 10 (2006), 1293-1303] and many authors.
\end{abstract}

1. Introduction. Let $H$ be a real Hilbert space with inner product $\langle\cdot, \cdot\rangle$ and norm $\|\cdot\|$. Let $C$ be a nonempty closed convex subset of $H$ and let $P_{C}$ be the metric projection of

2010 Mathematics Subject Classification: Primary 47H09; 47H10; Secondary 46C05, 47D03.

Key words and phrases: fixed point, hybrid projection method, monotone mapping, nonexpansive mapping, variational inequality.

The paper is in final form and no version of it will be published elsewhere. 
$H$ onto $C$. A mapping $S: C \rightarrow C$ is said to be nonexpansive if

$$
\|S x-S y\| \leq\|x-y\|,
$$

for all $x, y \in C$. We denote by $F(S)$ the set of fixed points of $S$. A mapping $A$ of $C$ into $H$ is called monotone if

$$
\langle A u-A v, u-v\rangle \geq 0,
$$

for all $u, v \in C$. A is called $\alpha$-inverse-strongly-monotone if there exists a positive real number $\alpha$ such that

$$
\langle A u-A v, u-v\rangle \geq \alpha\|A u-A v\|^{2},
$$

for all $u, v \in C$. A is called $k$-Lipschitz-continuous if there exists a positive constant $k$ such that for all $u, v \in C$

$$
\|A u-A v\| \leq k\|u-v\| .
$$

Obviously, it is easy to see that every $\alpha$-inverse-strongly-monotone mapping $A$ is monotone and Lipschitz continuous.

The classical variational inequality problem is to find $u \in C$ such that $\langle v-u, A u\rangle \geq 0$ for all $v \in C$. We denote by $\operatorname{VI}(A, C)$ the set of solutions of this variational inequality problem. The variational inequality has been extensively studied in the literature. See, e.g. $[17,18]$ and the references therein.

Construction of fixed points of nonexpansive mapping is an important subject in the theory of nonexpansive mappings. However, the sequence $\left\{S^{n} x\right\}_{n=0}^{\infty}$ of iterates of the mapping $S$ at a point $x \in C$ may not converge even in weak topology. More precisely, Mann's iterated procedure is a sequence $\left\{x_{n}\right\}$ which is generated in the following recursive way:

$$
x_{n+1}=\alpha_{n} x_{n}+\left(1-\alpha_{n}\right) S x_{n}, \quad n \geq 0,
$$

where the initial guess $x_{0} \in C$ is chosen arbitrary. However, we note that Mann's iterations have only weak convergence even in a Hilbert space [9].

For finding an element of $F(S) \cap \operatorname{VI}(C, A)$ under the assumption that a set $C \subset H$ is closed and convex, a mapping $S$ of $C$ into itself is nonexpansive, and a mapping $A$ of $C$ into $H$ is $\alpha$-inverse-strongly-monotone, Takahashi and Toyoda [16] introduced the following iterative scheme:

$$
\begin{aligned}
x_{0} & =x \in C, \\
x_{n+1} & =\alpha_{n} x_{n}+\left(1-\alpha_{n}\right) S P_{C}\left(x_{n}-\lambda_{n} A x_{n}\right),
\end{aligned}
$$

for every $n \geq 0$ where $\left\{\alpha_{n}\right\}$ is a sequence in $(0,1)$ and $\left\{\lambda_{n}\right\}$ is a sequence in $(0,2 \alpha)$. They proved that if $F(S) \cap \mathrm{VI}(C, A) \neq \emptyset$, then the sequence $\left\{x_{n}\right\}$ generated by $(6)$ converges weakly to some $z \in F(S) \cap \mathrm{VI}(C, A)$.

In 2006, motivated by the idea of Korpelevich's extragradient method [8], Nadezhkina and Takahashi [11] introduced an iterative scheme for finding an element of $F(S) \cap$ $\operatorname{VI}(C, A)$. They proved the following weak convergence result.

TheOREM 1.1 ([11, Theorem 3.1]). Let $C$ be a nonempty closed convex subset of a real Hilbert space $H$. Let $A$ be a monotone and $k$-Lipschitz-continuous mapping of $C$ into $H$. 
Let $S$ be a nonexpansive mappings from $C$ into itself such that $F(S) \cap \operatorname{VI}(C, A) \neq \emptyset$. Let $\left\{x_{n}\right\}$ and $\left\{y_{n}\right\}$ be sequences in $C$ defined as follows:

$$
\begin{aligned}
x_{0} & =x \in C, \\
y_{n} & =P_{C}\left(x_{n}-\lambda_{n} A x_{n}\right), \\
x_{n+1} & =\alpha_{n} x_{n}+\left(1-\alpha_{n}\right) S P_{C}\left(x_{n}-\lambda_{n} A y_{n}\right) \quad \forall n \geq 0,
\end{aligned}
$$

where $\left\{\lambda_{n}\right\} \subset[a, b]$ for some $a, b \in(0,1 / k)$ and $\left\{\alpha_{n}\right\} \subset(c, d)$ for some $c, d \in(0,1)$. Then the sequences $\left\{x_{n}\right\}$ and $\left\{y_{n}\right\}$ converge weakly to the same point $z \in F(S) \cap \operatorname{VI}(C, A)$, where $z=\lim _{n \rightarrow \infty} P_{F(S) \cap \mathrm{VI}(C, A)} x_{n}$.

Recently, Zeng and Yao [20] proved the following strong convergence theorem:

$$
\begin{aligned}
x_{0} & =x \in C, \\
y_{n} & =P_{C}\left(x_{n}-\lambda_{n} A x_{n}\right), \\
x_{n+1} & =\alpha_{n} x_{0}+\left(1-\alpha_{n}\right) S P_{C}\left(x_{n}-\lambda_{n} A y_{n}\right) \quad \forall n \geq 0,
\end{aligned}
$$

where $\left\{\lambda_{n}\right\}$ and $\left\{\alpha_{n}\right\}$ satisfy the following conditions:

(i) $\left\{\lambda_{n} k\right\} \subset(0,1-\delta)$ for some $\delta \in(0,1)$;

(ii) $\left\{\alpha_{n}\right\} \subset(0,1), \sum_{n=1}^{\infty} \alpha_{n}=\infty, \lim _{n \rightarrow \infty} \alpha_{n}=0$.

They proved that the sequences $\left\{x_{n}\right\}$ and $\left\{y_{n}\right\}$ converge strongly to the same point $P_{F(S) \cap \mathrm{VI}(C, A)} x_{0}$ provided that $\lim _{n \rightarrow \infty}\left\|x_{n+1}-x_{n}\right\|=0$.

On the other hand, motivated by the idea of Nakajo and Takahashi [12], Nadezhkina and Takahashi [10] introduced the following iterative scheme for finding an element of $F(S) \cap \mathrm{VI}(C, A)$ and proved the following strong convergence theorem by using the CQ hybrid method. Recently, Takahashi, Takeuchi and Kubota [15] proved the following strong convergence theorem by using the new hybrid method in mathematical programming.

THEOREM 1.2 ([15, Theorem 3.3]). Let $H$ be a Hilbert space and let $C$ be a nonempty closed convex subset of $H$. Let $\left\{T_{n}\right\}$ be a sequence of nonexpansive mappings from $C$ into itself such that $\bigcap_{n=1}^{\infty} F\left(T_{n}\right) \neq \emptyset$ and let $x_{0} \in H$. For $C_{1}=C$ and $x_{1}=P_{C_{1}} x_{0}$, define a sequence as follows:

$$
\begin{aligned}
y_{n} & =\alpha_{n} x_{n}+\left(1-\alpha_{n}\right) T_{n} x_{n}, \\
C_{n+1} & =\left\{z \in C_{n}:\left\|y_{n}-z\right\| \leq\left\|x_{n}-z\right\|\right\}, \\
x_{n+1} & =P_{C_{n+1}} x_{0}, \quad n \geq 1,
\end{aligned}
$$

where $0 \leq \alpha_{n}<\alpha<1$ for all $n \geq 1$. Let $T$ be a mapping of $C$ into itself such that $F(T)=\bigcap_{n=1}^{\infty} F\left(T_{n}\right)$. Suppose that for each bounded sequence $\left\{z_{n}\right\} \subset C, \lim _{n \rightarrow \infty} \| z_{n+1}-$ $T_{n} z_{n} \|=0$ implies that $\lim _{n \rightarrow \infty}\left\|z_{n}-T_{m} z_{n}\right\|=0$ for each $m \in \mathbb{N}$. Then $\left\{x_{n}\right\}$ converges strongly to $z_{0}=P_{F(T)} x_{0}$.

Inspired and motivated by the previously mentioned results, the purpose of this paper is to improve and generalize the processes (7) and (8) to the new general processes for finding a common element of the set of common fixed points of a countable family of nonexpansive mappings and the set of solutions of the variational inequality problem for a monotone Lipschitz-continuous mapping. Let $C$ be nonempty closed convex subset of a 
Hilbert space $H, A$ be a monotone and $k$-Lipschitz-continuous mapping of $C$ into $H$ and $\left\{S_{n}\right\}$ be a sequence of nonexpansive mappings from $C$ into itself such that $\bigcap_{n=1}^{\infty} F\left(S_{n}\right) \cap$ $\mathrm{VI}(C, A) \neq \emptyset$. Define $\left\{x_{n}\right\}$ in two ways:

$$
\begin{aligned}
x_{0} & =x \in C, \\
y_{n} & =P_{C}\left(x_{n}-\lambda_{n} A x_{n}\right), \\
z_{n} & =\alpha_{n} x_{n}+\left(1-\alpha_{n}\right) S_{n} P_{C}\left(x_{n}-\lambda_{n} A y_{n}\right), \\
C_{n} & =\left\{z \in C:\left\|z_{n}-z\right\| \leq\left\|x_{n}-z\right\|\right\}, \\
Q_{n} & =\left\{z \in C:\left\langle x_{n}-z, x_{0}-x_{n}\right\rangle \geq 0\right\}, \\
x_{n+1} & =P_{C_{n} \cap Q_{n}} x_{0}, \quad n=0,1,2, \ldots,
\end{aligned}
$$

and

$$
\begin{aligned}
x_{0} \in H, & C_{1}=C, \quad x_{1}=P_{C_{1}} x_{0}, \\
y_{n}= & P_{C}\left(x_{n}-\lambda_{n} A x_{n}\right), \\
z_{n}= & \alpha_{n} x_{n}+\left(1-\alpha_{n}\right) S_{n} P_{C}\left(x_{n}-\lambda_{n} A y_{n}\right), \\
C_{n+1}= & \left\{z \in C_{n}:\left\|z_{n}-z\right\| \leq\left\|x_{n}-z\right\|\right\}, \\
x_{n+1}= & P_{C_{n+1}} x_{0}, \quad n \geq 1,
\end{aligned}
$$

where $0 \leq \alpha_{n}<c<1$ and $0<a<\lambda_{n}<b<\frac{1}{k}$ for all $n=1,2,3 \ldots$

We shall prove that both iterations (9) and (10) converge strongly to a point $z$ in $\bigcap_{n=1}^{\infty} F\left(S_{n}\right) \cap \operatorname{VI}(C, A)$. Our results extend and improve the corresponding ones announced by Nadezhkina and Takahashi [10] and Zeng and Yao [20].

2. Preliminaries. Let $H$ be a real Hilbert space. Then

$$
\|x-y\|^{2}=\|x\|^{2}-\|y\|^{2}-2\langle x-y, y\rangle
$$

and

$$
\|\lambda x+(1-\lambda) y\|^{2}=\lambda\|x\|^{2}+(1-\lambda)\|y\|^{2}-\lambda(1-\lambda)\|x-y\|^{2}
$$

for all $x, y \in H$ and $\lambda \in[0,1]$. It is also known that $H$ satisfies the Opial condition [13], that is, for any sequence $\left\{x_{n}\right\}$ with $x_{n} \rightarrow x$, the inequality

$$
\liminf _{n \rightarrow \infty}\left\|x_{n}-x\right\|<\liminf _{n \rightarrow \infty}\left\|x_{n}-y\right\|
$$

holds for every $y \in H$ with $y \neq x$.

Let $C$ be a closed convex subset of $H$. For every point $x \in H$, there exists a unique nearest point in $C$, denoted by $P_{C} x$, such that

$$
\left\|x-P_{C} x\right\| \leq\|x-y\| \quad \text { for all } y \in C .
$$

$P_{C}$ is called the metric projection of $H$ onto $C$. It is well known that $P_{C}$ is a nonexpansive mapping of $H$ onto $C$ and satisfies

$$
\left\langle x-y, P_{C} x-P_{C} y\right\rangle \geq\left\|P_{C} x-P_{C} y\right\|^{2}
$$

for every $x, y \in H$. Moreover, $P_{C} x$ is characterized by the following properties: $P_{C} x \in C$ and

$$
\left\langle x-P_{C} x, y-P_{C} x\right\rangle \leq 0,
$$




$$
\|x-y\|^{2} \geq\left\|x-P_{C} x\right\|^{2}+\left\|y-P_{C} x\right\|^{2}
$$

for all $x \in H, y \in C$.

In the context of the variational inequality problem, this implies that

$$
u \in \mathrm{VI}(A, C) \Leftrightarrow u=P_{C}(u-\lambda A u) \text {, for all } \lambda>0 .
$$

A set valued mapping $T: H \rightarrow 2^{H}$ is called monotone if for all $x, y \in H, f \in T x$ and $g \in T y$ imply $\langle x-y, f-g\rangle \geq 0$. A monotone mapping $T: H \rightarrow 2^{H}$ is maximal if the graph $G(T)$ of $T$ is not properly contained in the graph of any other monotone mapping. It known that a monotone mapping $T$ is maximal if and only if for $(x, f) \in H \times H$, $\langle x-y, f-h\rangle \geq 0$ for every $(y, g) \in G(T)$ implies $f \in T x$. Let $A$ be an inverse-strongly monotone mapping of $C$ into $H$ and let $N_{C} v$ be the normal cone to $C$ at $v \in C$, i.e.,

$$
N_{C} v=\{w \in H:\langle v-u, w\rangle \geq 0 \forall u \in C\},
$$

and define

$$
T v= \begin{cases}A v+N_{C} v, & v \in C, \\ \emptyset, & v \notin C .\end{cases}
$$

Then $T$ is maximal monotone and $0 \in T v$ if and only if $v \in \operatorname{VI}(C, A)$; see [14].

The following lemma will be useful for proving the convergence result of this paper.

LEMMA 2.1 (Browder [2]). Let $C$ be a non-empty closed convex subset of a uniformly convex Banach space $E$, and suppose $S: C \rightarrow E$ is nonexpansive. Then the mapping $I-S$ is demiclosed at zero, i.e.,

$$
x_{n} \rightarrow x, \quad x_{n}-S x_{n} \rightarrow 0 \quad \text { implies } \quad x=S x .
$$

Lemma 2.2 ([1], Lemma 3.2). Let $C$ be a nonempty closed subset of a Banach space and let $\left\{T_{n}\right\}$ be a sequence of nonexpansive mappings of $C$ into itself. Suppose that $\sum_{n=1}^{\infty} \sup \left\{\left\|T_{n+1} z-T_{n} z\right\|: z \in C\right\}<\infty$. Then, for each $y \in C,\left\{T_{n} y\right\}$ converges strongly to some point of $C$. Moreover, let $T$ be a mapping of $C$ into itself defined by

$$
T y=\lim _{n \rightarrow \infty} T_{n} y \quad \text { for all } y \in C .
$$

Then $\lim _{n \rightarrow \infty} \sup \left\{\left\|T_{n} z-T z\right\|: z \in C\right\}=0$.

3. Main theorems. In this section, we prove strong convergence theorems by hybrid methods for finding a common fixed points of $k$-Lipschitz-continuous monotone mappings and a family of nonexpansive mappings in Hilbert spaces.

THEOREM 3.1. Let $C$ be a nonempty closed convex subset of a real Hilbert space H. Let $A$ be monotone and $k$-Lipschitz-continuous mapping of $C$ into $H$. Let $\left\{S_{n}\right\}$ be a sequence of nonexpansive mappings from $C$ into itself such that $\bigcap_{n=1}^{\infty} F\left(S_{n}\right) \cap \operatorname{VI}(C, A)$ is nonempty. Let $\left\{x_{n}\right\},\left\{y_{n}\right\}$ and $\left\{z_{n}\right\}$ be sequences in $C$ defined as follows:

$$
\begin{gathered}
x_{0}=x \in C, \\
y_{n}=P_{C}\left(x_{n}-\lambda_{n} A x_{n}\right), \\
z_{n}=\alpha_{n} x_{n}+\left(1-\alpha_{n}\right) S_{n} P_{C}\left(x_{n}-\lambda_{n} A y_{n}\right), \\
C_{n}=\left\{z \in C:\left\|z_{n}-z\right\| \leq\left\|x_{n}-z\right\|\right\},
\end{gathered}
$$




$$
\begin{gathered}
Q_{n}=\left\{z \in C:\left\langle x_{n}-z, x_{0}-x_{n}\right\rangle \geq 0\right\}, \\
x_{n+1}=P_{C_{n} \cap Q_{n}} x_{0}, \quad n=0,1,2, \ldots,
\end{gathered}
$$

where $0 \leq \alpha_{n}<c<1$ and $0<a<\lambda_{n}<b<\frac{1}{k}$ for all $n=1,2,3 \ldots$ Let $\sum_{n=1}^{\infty} \sup \left\{\left\|S_{n+1} z-S_{n} z\right\|: z \in B\right\}<\infty$ for any bounded subset $B$ of $C$ and $S$ be a mapping of $C$ into itself defined by $S z=\lim _{n \rightarrow \infty} S_{n} z$ for all $z \in C$ and suppose that $F(S)=\bigcap_{n=1}^{\infty} F\left(S_{n}\right)$. Then $\left\{x_{n}\right\},\left\{y_{n}\right\}$ and $\left\{z_{n}\right\}$ converge strongly to $P_{F(S) \cap \mathrm{VI}(C, A)} x_{0}$.

Proof. We divide the proof into four steps.

Step 1. We claim that $C_{n}$ and $Q_{n}$ are closed and convex for all $n \geq 0$, and $F(S) \cap$ $\mathrm{VI}(C, A) \subset C_{n} \cap Q_{n}$, for all $n \geq 0$. From the definition of $C_{n}$ and $Q_{n}$, it is obvious that $C_{n}$ is closed and $Q_{n}$ is closed and convex for all $n \geq 0$. Since $C_{n}=\{z \in C$ : $\left.\left\|y_{n}-x_{n}\right\|^{2}+2\left\langle y_{n}-x_{n}, x_{n}-z\right\rangle \leq 0\right\}$, we deduce that $C_{n}$ is convex for all $n \geq 0$.

Next, we show that

$$
F(S) \cap \mathrm{VI}(C, A) \subset C_{n}, \quad \forall n \geq 0 .
$$

Put $v_{n}=P_{C}\left(x_{n}-\lambda_{n} A y_{n}\right)$ for all $n \geq 0$. Let $u \in F(S) \cap \operatorname{VI}(C, A)$. Thus, we have $u=P_{C}\left(u-\lambda_{n} A u\right)$. From (16) and the monotonicity of $A$, we have

$$
\begin{aligned}
\left\|v_{n}-u\right\|^{2} \leq & \left\|x_{n}-\lambda_{n} A y_{n}-u\right\|^{2}-\left\|x_{n}-\lambda_{n} A y_{n}-v_{n}\right\|^{2} \\
= & \left\|x_{n}-u\right\|^{2}-\left\|x_{n}-v_{n}\right\|^{2}+2 \lambda_{n}\left\langle A y_{n}, u-v_{n}\right\rangle \\
= & \left\|x_{n}-u\right\|^{2}-\left\|x_{n}-v_{n}\right\|^{2} \\
& \quad+2 \lambda_{n}\left(\left\langle A y_{n}-A u, u-y_{n}\right\rangle+\left\langle A u, u-y_{n}\right\rangle\right)+\left\langle A y_{n}, y_{n}-v_{n}\right\rangle \\
\leq & \left\|x_{n}-u\right\|^{2}-\left\|x_{n}-v_{n}\right\|^{2}+2 \lambda_{n}\left\langle A y_{n}, y_{n}-v_{n}\right\rangle \\
= & \left\|x_{n}-u\right\|^{2}-\left\|x_{n}-y_{n}\right\|^{2}-2\left\langle x_{n}-y_{n}, y_{n}-v_{n}\right\rangle-\left\|y_{n}-v_{n}\right\|^{2} \\
& \quad+2 \lambda_{n}\left\langle A y_{n}, y_{n}-v_{n}\right\rangle \\
= & \left\|x_{n}-u\right\|^{2}-\left\|x_{n}-y_{n}\right\|^{2}-\left\|y_{n}-v_{n}\right\|^{2} \\
& +2\left\langle x_{n}-\lambda_{n} A y_{n}-y_{n}, v_{n}-y_{n}\right\rangle .
\end{aligned}
$$

Since $y_{n}=P_{C}\left(x_{n}-\lambda_{n} A x_{n}\right)$ and $A$ is $k$-Lipschitz-continuous, it follows that

$$
\begin{aligned}
\left\langle x_{n}-\lambda_{n} A y_{n}-y_{n}, v_{n}-y_{n}\right\rangle & =\left\langle x_{n}-\lambda_{n} A x_{n}-y_{n}, v_{n}-y_{n}\right\rangle+\left\langle\lambda_{n} A x_{n}-\lambda_{n} A y_{n}, v_{n}-y_{n}\right\rangle \\
& \leq\left\langle\lambda_{n} A x_{n}-\lambda_{n} A y_{n}, v_{n}-y_{n}\right\rangle \\
& \leq \lambda_{n} k\left\|x_{n}-y_{n}\right\|\left\|v_{n}-y_{n}\right\| .
\end{aligned}
$$

So, we obtain

$$
\begin{aligned}
\left\|v_{n}-u\right\|^{2} \leq & \left\|x_{n}-u\right\|^{2}-\left\|x_{n}-y_{n}\right\|^{2}-\left\|y_{n}-v_{n}\right\|^{2} \\
& +2 \lambda_{n} k\left\|x_{n}-y_{n}\right\|\left\|v_{n}-y_{n}\right\| \\
\leq & \left\|x_{n}-u\right\|^{2}-\left\|x_{n}-y_{n}\right\|^{2}-\left\|y_{n}-v_{n}\right\|^{2} \\
& \quad+\lambda_{n} k\left(\left\|x_{n}-y_{n}\right\|^{2}-\left\|v_{n}-y_{n}\right\|^{2}\right) \\
= & \left\|x_{n}-u\right\|^{2}+\left(\lambda_{n} k-1\right)\left\|x_{n}-y_{n}\right\|^{2}-\left(1+\lambda_{n} k\right)\left\|y_{n}-v_{n}\right\|^{2} \\
\leq & \left\|x_{n}-u\right\|^{2} .
\end{aligned}
$$


Therefore, from (21), $z_{n}=\alpha_{n} x_{n}-\left(1-\alpha_{n}\right) S_{n} v_{n}$ and $u=S_{n} u$, we have

$$
\begin{aligned}
\left\|z_{n}-u\right\|^{2} & =\left\|\alpha_{n}\left(x_{n}-u\right)+\left(1-\alpha_{n}\right)\left(S_{n} v_{n}-u\right)\right\|^{2} \\
& \leq \alpha_{n}\left\|x_{n}-u\right\|^{2}+\left(1-\alpha_{n}\right)\left\|S_{n} v_{n}-u\right\|^{2} \\
& \leq \alpha_{n}\left\|x_{n}-u\right\|^{2}+\left(1-\alpha_{n}\right)\left\|v_{n}-u\right\|^{2} \\
& \leq \alpha_{n}\left\|x_{n}-u\right\|^{2}+\left(1-\alpha_{n}\right)\left(\left\|x_{n}-u\right\|^{2}+\left(\lambda_{n} k-1\right)\left\|x_{n}-y_{n}\right\|^{2}\right) \\
& \leq\left\|x_{n}-u\right\|^{2}+\left(1-\alpha_{n}\right)\left(\lambda_{n} k-1\right)\left\|x_{n}-y_{n}\right\|^{2} \\
& \leq\left\|x_{n}-u\right\|^{2}
\end{aligned}
$$

for all $n \geq 0$ and hence $u \in C_{n}$. So $F(S) \cap \operatorname{VI}(C, A) \subset C_{n}$, for all $n \geq 0$.

Next, we show that

$$
F(S) \cap \operatorname{VI}(C, A) \subset Q_{n} \quad \text { for all } n \geq 0 .
$$

We prove this by induction. For $n=0$, we have $F(S) \cap \operatorname{VI}(C, A) \subset C Q_{0}$. Suppose that $F(S) \cap \operatorname{VI}(C, A) \subset Q_{n}$. Then $\emptyset \neq F(S) \cap \operatorname{VI}(C, A) \subset C_{n} \cap Q_{n}$ and there exists a unique element $x_{n+1} \in C_{n} \cap Q_{n}$ such that $x_{n+1}=P_{C_{n} \cap Q_{n}} x_{0}$. Then

$$
\left\langle x_{n+1}-z, x_{0}-x_{n+1}\right\rangle \geq 0
$$

for each $z \in C_{n} \cap Q_{n}$. In particular,

$$
\left\langle x_{n+1}-p, x_{0}-x_{n+1}\right\rangle \geq 0
$$

for each $p \in F(S) \cap \operatorname{VI}(C, A)$. It follows that $F(S) \cap \operatorname{VI}(C, A) \subset Q_{n+1}$ and hence (23) holds. Therefore

$$
F(S) \cap \mathrm{VI}(C, A) \subset C_{n} \cap Q_{n} \quad \text { for all } n \geq 0 .
$$

This implies that $\left\{x_{n}\right\}$ is well-defined.

Step 2. We claim that the following statements hold:

1. $\left\{x_{n}\right\}$ is bounded;

2. $\left\|x_{n+1}-x_{n}\right\| \rightarrow 0$.

It follows from the definition of $Q_{n}$ that $x_{n}=P_{Q_{n}} x_{0}$. Therefore

$$
\left\|x_{n}-x_{0}\right\| \leq\left\|z-x_{0}\right\| \quad \text { for all } z \in Q_{n} \text { and all } n \geq 0 .
$$

Let $z \in F(S) \cap \operatorname{VI}(C, A)$. Then

$$
\left\|x_{n}-x_{0}\right\| \leq\left\|z-x_{0}\right\| \quad \text { for all } n \geq 0 .
$$

On the other hand, from $x_{n+1}=P_{C_{n} \cap Q_{n}} x_{0} \in Q_{n}$, we have

$$
\left\|x_{n}-x_{0}\right\| \leq\left\|x_{n+1}-x_{0}\right\| \quad \text { for all } n \geq 0 .
$$

Therefore $\left\{\left\|x_{n}-x_{0}\right\|\right\}$ is nondecreasing and bounded. So $\lim _{n \rightarrow \infty}\left\|x_{n}-x_{0}\right\|$ exists. This implies that $\left\{x_{n}\right\}$ is bounded. From (21) and (22), we also obtain that $\left\{z_{n}\right\}$ and $\left\{v_{n}\right\}$ are bounded.

Since $x_{n+1}=P_{C_{n} \cap Q_{n}} x_{0} \in Q_{n}$, we have $\left\langle x_{n}-x_{n+1}, x_{0}-x_{n}\right\rangle \geq 0$. It follows from (11) that

$$
\begin{aligned}
\left\|x_{n+1}-x_{n}\right\|^{2} & =\left\|\left(x_{n+1}-x_{0}\right)-\left(x_{n}-x_{0}\right)\right\|^{2} \\
& =\left\|x_{n+1}-x_{0}\right\|^{2}-\left\|x_{n}-x_{0}\right\|^{2}-2\left\langle x_{n+1}-x_{n}, x_{n}-x_{0}\right\rangle
\end{aligned}
$$




$$
\leq\left\|x_{n+1}-x_{0}\right\|^{2}-\left\|x_{n}-x_{0}\right\|^{2}
$$

for all $n=0,1,2 \ldots$ This implies that

$$
\lim _{n \rightarrow \infty}\left\|x_{n+1}-x_{n}\right\|=0 .
$$

Step 3. We claim that the following statements hold:

1. $\lim _{n \rightarrow \infty}\left\|x_{n}-z_{n}\right\|=0$ and $\lim _{n \rightarrow \infty}\left\|x_{n}-y_{n}\right\|=0$;

2. $\lim _{n \rightarrow \infty}\left\|S x_{n}-x_{n}\right\|=0$ and $\lim _{n \rightarrow \infty}\left\|S_{n} x_{n}-x_{n}\right\|=0$.

Since $x_{n+1} \in C_{n}$, we have $\left\|z_{n}-x_{n+1}\right\| \leq\left\|x_{n}+x_{n+1}\right\|$. This implies that

$$
\begin{aligned}
\left\|x_{n}-S_{n} v_{n}\right\| & =\frac{1}{1-\alpha_{n}}\left\|z_{n}-x_{n}\right\| \\
& \leq \frac{1}{1-\alpha_{n}}\left(\left\|z_{n}-x_{n+1}\right\|+\left\|x_{n}-x_{n+1}\right\|\right) \\
& \leq \frac{2}{1-\alpha_{n}}\left\|x_{n}-x_{n+1}\right\|
\end{aligned}
$$

for all $n \geq 0$. From (24) and $0 \leq \alpha_{n}<c<1$, we get

$$
\lim _{n \rightarrow \infty}\left\|x_{n}-S_{n} v_{n}\right\|=0 \text {. }
$$

Since $\left\|x_{n}-z_{n}\right\| \leq\left\|x_{n}-x_{n+1}\right\|+\left\|x_{n+1}-z_{n}\right\| \leq 2\left\|x_{n}-x_{n+1}\right\|, \quad \forall n \geq 0$, it follows that

$$
\lim _{n \rightarrow \infty}\left\|x_{n}-z_{n}\right\|=0 \text {. }
$$

For each $u \in F(S) \cap \operatorname{VI}(C, A)$, from (22), we obtain

$$
\left\|z_{n}-u\right\|^{2} \leq\left\|x_{n}-u\right\|^{2}+\left(1-\alpha_{n}\right)\left(\lambda_{n} k-1\right)\left\|x_{n}-y_{n}\right\|^{2} .
$$

Thus, we have

$$
\begin{aligned}
\left\|x_{n}-y_{n}\right\|^{2} & \leq \frac{1}{\left(1-\alpha_{n}\right)\left(\lambda_{n} k\right)}\left(\left\|x_{n}-u\right\|^{2}-\left\|z_{n}-u\right\|^{2}\right) \\
& \leq \frac{1}{\left(1-\alpha_{n}\right)\left(\lambda_{n} k\right)}\left(\left\|x_{n}-u\right\|+\left\|z_{n}-u\right\|\right)\left\|x_{n}-z_{n}\right\|
\end{aligned}
$$

Since $\left\|x_{n}-z_{n}\right\| \rightarrow 0$ and the sequences $\left\{x_{n}\right\},\left\{z_{n}\right\}$ are bounded, we obtain $\left\|x_{n}-y_{n}\right\| \rightarrow 0$.

As $A$ is $k$-Lipschitz-continuous, we have

$$
\begin{aligned}
\left\|y_{n}-v_{n}\right\| & =\left\|P_{C}\left(x_{n}-\lambda_{n} A x_{n}\right)-P_{C}\left(x_{n}-\lambda_{n} A y_{n}\right)\right\| \\
& \leq \lambda_{n}\left\|A x_{n}-A y_{n}\right\| \\
& \leq \lambda_{n} k\left\|x_{n}-y_{n}\right\| \rightarrow 0 \text { as } n \rightarrow \infty
\end{aligned}
$$

This implies that

$$
\lim _{n \rightarrow \infty}\left\|y_{n}-v_{n}\right\|=0
$$

Moreover, we note that

$$
\begin{aligned}
\left\|S_{n} x_{n}-x_{n}\right\| & \leq\left\|S_{n} x_{n}-S_{n} y_{n}\right\|+\left\|S_{n} y_{n}-S_{n} v_{n}\right\|+\left\|S_{n} v_{n}-x_{n}\right\| \\
& \leq\left\|x_{n}-y_{n}\right\|+\left\|y_{n}-v_{n}\right\|+\left\|S_{n} v_{n}-x_{n}\right\| .
\end{aligned}
$$

From (25), (26) and (27), we obtain

$$
\lim _{n \rightarrow \infty}\left\|S_{n} x_{n}-x_{n}\right\|=0 .
$$


Since $\sum_{n=1}^{\infty} \sup \left\{\left\|S z-S_{n} z\right\|: z \in\left\{x_{n}\right\}\right\}<\infty$, and

$$
\begin{aligned}
\left\|S x_{n}-x_{n}\right\| & \leq\left\|S x_{n}-S_{n} x_{n}\right\|+\left\|S_{n} x_{n}-x_{n}\right\| \\
& \leq \sup \left\{\left\|S z-S_{n} z\right\|: z \in\left\{x_{n}\right\}\right\}+\left\|S_{n} x_{n}-x_{n}\right\|,
\end{aligned}
$$

it follows that

$$
\lim _{n \rightarrow \infty}\left\|S x_{n}-x_{n}\right\|=0 .
$$

Step 4. We claim that $\left\{x_{n}\right\}$ converge strongly to $z_{0}$, where $z_{0}=P_{F(S) \cap \mathrm{VI}(C, A)} x_{0}$. Since $\left\{x_{n}\right\}$ is bounded, there exists a subsequence $\left\{x_{n_{k}}\right\}$ of $\left\{x_{n}\right\}$ which converges weakly to $z$. By [11, Theorem 3.1 pp. 197-198], we can show that $z \in \operatorname{VI}(C, A)$. Next, we show that $z \in F(S)$. Let $\left\{x_{n_{k}}\right\}$ be another subsequence of $\left\{x_{n}\right\}$ which converges weakly to $z$. Since $I-S$ is demiclosed, it follows by Lemma 2.1 that $z \in F(S)$. Hence $z \in F(S) \cap \operatorname{VI}(C, A)$.

Since $x_{n}=P_{Q_{n}} x_{0}$ and $z_{0} \in F(S) \cap \operatorname{VI}(C, A) \subset Q_{n}$, we have

$$
\left\|x_{n}-x_{0}\right\| \leq\left\|z_{0}-x_{0}\right\|
$$

It follows from $z_{0}=P_{F(S) \cap \mathrm{VI}(C, A)} x_{0}$ and the lower semicontinuity of the norm that

$$
\left\|z_{0}-x_{0}\right\| \leq\left\|z-x_{0}\right\| \leq \liminf _{k \rightarrow \infty}\left\|x_{n_{k}}-x_{0}\right\| \leq \limsup _{k \rightarrow \infty}\left\|x_{n_{k}}-x_{0}\right\| \leq\left\|z_{0}-x_{0}\right\| .
$$

Thus, we obtain that $\lim _{k \rightarrow \infty}\left\|x_{n_{k}}-x_{0}\right\|=\left\|z-x_{0}\right\|=\left\|z_{0}-x_{0}\right\|$.

Using the Kadec-Klee property of $H$, we obtain that

$$
\lim _{k \rightarrow \infty} x_{n_{k}}=z=z_{0} .
$$

Since $\left\{x_{n_{k}}\right\}$ is an arbitrary subsequence of $\left\{x_{n}\right\}$, we can conclude that $\left\{x_{n}\right\}$ converges strongly to $z_{0}$, where $z_{0}=P_{F(S) \cap \mathrm{VI}(C, A)} x_{0}$. So, from $\left\|x_{n}-y_{n}\right\| \rightarrow 0$ and $\left\|x_{n}-z_{n}\right\| \rightarrow 0$, we infer that both $\left\{y_{n}\right\}$ and $\left\{z_{n}\right\}$ converge to $z_{0} \in P_{F(T) \cap \mathrm{VI}(C, A)} x_{0}$.

Setting $S_{n} \equiv S$ in Theorem 3.1, we have the following result.

Theorem 3.2 (Nadezhkina and Takahashi [10, Theorem 3.1]). Let $C$ be a nonempty closed convex subset of a real Hilbert space $H$. Let $A$ be monotone and $k$-Lipschitzcontinuous mapping of $C$ into $H$. Let $S$ be a nonexpansive mapping from $C$ into itself such that $F(S) \cap \operatorname{VI}(C, A) \neq \emptyset$. Let $\left\{x_{n}\right\},\left\{y_{n}\right\}$ and $\left\{z_{n}\right\}$ be sequences in $C$ defined as follows:

$$
\begin{aligned}
x_{0} & =x \in C, \\
y_{n} & =P_{C}\left(x_{n}-\lambda_{n} A x_{n}\right), \\
z_{n} & =\alpha_{n} x_{n}+\left(1-\alpha_{n}\right) S P_{C}\left(x_{n}-\lambda_{n} A y_{n}\right), \\
C_{n} & =\left\{z \in C:\left\|z_{n}-z\right\| \leq\left\|x_{n}-z\right\|\right\}, \\
Q_{n} & =\left\{z \in C:\left\langle x_{n}-z, x_{0}-x_{n}\right\rangle \geq 0\right\}, \\
x_{n+1} & =P_{C_{n} \cap Q_{n}} x_{0}, \quad n=0,1,2, \ldots,
\end{aligned}
$$

where $0 \leq \alpha_{n}<c<1$ and $0<a<\lambda_{n}<b<\frac{1}{k}$ for all $n=1,2,3 \ldots$ Then $\left\{x_{n}\right\},\left\{y_{n}\right\}$ and $\left\{z_{n}\right\}$ converge strongly to $P_{F(S) \cap \mathrm{VI}(C, A)} x_{0}$.

Setting $P_{C}\left(I-\lambda_{n} A\right)=I$ in Theorem 3.2, we have the following theorem. 
Theorem 3.3 (Nakajo and Takahashi [12]). Let $C$ be a nonempty closed convex subset of a real Hilbert space $H$ and let $S$ be a nonexpansive mapping from $C$ into itself such that $F(S) \cap A^{-1} 0 \neq \emptyset$. Suppose $x_{1}=x \in C$ and $\left\{x_{n}\right\}$ is given by

$$
\begin{aligned}
y_{n} & =\alpha_{n} x_{n}+\left(1-\alpha_{n}\right) S x_{n}, \\
C_{n} & =\left\{z \in C:\left\|y_{n}-z\right\| \leq\left\|x_{n}-z\right\|\right\}, \\
Q_{n} & =\left\{z \in C:\left\langle x_{n}-z, x_{0}-x_{n}\right\rangle \geq 0\right\}, \\
x_{n+1} & =P_{C_{n} \cap Q_{n}} x_{0}, \quad n=0,1,2, \ldots,
\end{aligned}
$$

where $0 \leq \alpha_{n}<c<1$. Then $\left\{x_{n}\right\}$ converges strongly to $P_{F(S)} x$.

THEOREM 3.4. Let $C$ be a nonempty closed convex subset of a real Hilbert space H. Let $A$ be monotone and $k$-Lipschitz-continuous mapping of $C$ into $H$. Let $\left\{S_{n}\right\}$ be a sequence of nonexpansive mappings from $C$ into itself such that $\bigcap_{n=1}^{\infty} F\left(S_{n}\right) \cap \operatorname{VI}(C, A) \neq \emptyset$ and let $x_{0} \in H$. For $C_{1}=C$ and $x_{1}=P_{C_{1}} x_{0}$, define a sequence $\left\{x_{n}\right\}$ of $C$ as follows:

$$
\begin{aligned}
y_{n} & =P_{C}\left(x_{n}-\lambda_{n} A x_{n}\right), \\
z_{n} & =\alpha_{n} x_{n}+\left(1-\alpha_{n}\right) S_{n} P_{C}\left(x_{n}-\lambda_{n} A y_{n}\right), \\
C_{n+1} & =\left\{z \in C_{n}:\left\|z_{n}-z\right\| \leq\left\|x_{n}-z\right\|\right\}, \\
x_{n+1} & =P_{C_{n+1}} x_{0}, \quad n=1,2,3 \ldots,
\end{aligned}
$$

where $0 \leq \alpha_{n}<c<1$ and $0<a<\lambda_{n}<b<2 \alpha$ for all $n=1,2,3 \ldots$ Let $\sum_{n=1}^{\infty} \sup \left\{\left\|S_{n+1} z-S_{n} z\right\|: z \in B\right\}<\infty$ for any bounded subset $B$ of $C$ and $S$ be a mapping of $C$ into itself defined by $S z=\lim _{n \rightarrow \infty} S_{n} z$ for all $z \in C$ and suppose that $F(S)=\bigcap_{n=1}^{\infty} F\left(S_{n}\right)$. Then $\left\{x_{n}\right\}$ converges strongly to $w=P_{F(S) \cap \mathrm{VI}(C, A)} x_{0}$.

Proof. We first show by induction that $F(S) \cap \mathrm{VI}(C, A) \subset C_{n}$ for all $n=1,2,3 \ldots$ It is obvious that $F(S) \cap \operatorname{VI}(C, A) \subset C=C_{1}$. Suppose that $F(S) \cap \operatorname{VI}(C, A) \subset C_{k}$ for each $k=1,2,3 \ldots$ Hence, for $u \in F(S) \cap \operatorname{VI}(C, A) \subset C_{k}$ we have $u=P_{C}\left(u-\lambda_{k+1} A u\right)$. Putting $v_{n}=P_{C}\left(x_{n}-\lambda_{n} A y_{n}\right)$ for all $n \geq 0$, as in the proof of Theorem 3.1, we can show that

$$
\left\|v_{n}-u\right\|^{2} \leq\left\|x_{n}-u\right\|^{2}+\left(\lambda_{n} k-1\right)\left\|x_{n}-y_{n}\right\|^{2} \leq\left\|x_{n}-u\right\|^{2}
$$

and

$$
\left\|z_{n}-u\right\|^{2} \leq\left\|x_{n}-u\right\|^{2}+\left(1-\alpha_{n}\right)\left(\lambda_{n} k-1\right)\left\|x_{n}-y_{n}\right\|^{2} \leq\left\|x_{n}-u\right\|^{2}
$$

for all $n \geq 0$. Thus $u \in C_{n}, n \geq 0$ and hence $F(S) \cap \operatorname{VI}(C, A) \subset C_{n}$, for all $n \geq 0$.

Next, we prove that $C_{n}$ is closed and convex for all $n=1,2,3 \ldots$ It is obvious that $C_{1}=C$ is closed and convex. Suppose that $C_{k}$ is closed and convex for some $k=1,2,3 \ldots$ For $z \in C_{k}$, we know that $\left\|z_{k}-z\right\| \leq\left\|x_{k}-z\right\|$ is equivalent to

$$
\left\|z_{k}-x_{k}\right\|^{2}+2\left\langle z_{k}-x_{k}, x_{k}-z\right\rangle \geq 0 \text {. }
$$

So, $C_{k+1}$ is closed and convex. Then, for any $n=1,2,3 \ldots, C_{n}$ is closed and convex. This implies that $\left\{x_{n}\right\}$ is well-defined. From $x_{n}=P_{C_{n}} x_{0}$, we have

$$
\left\langle x_{0}-x_{n}, x_{n}-y\right\rangle \geq 0
$$


for each $y \in C_{n}$. Using $F(S) \cap \operatorname{VI}(C, A) \subset C_{n}$, we also have

$$
\left\langle x_{0}-x_{n}, x_{n}-u\right\rangle \geq 0 \text { for each } u \in F(S) \cap \mathrm{VI}(C, A) \text { and } n=1,2,3 \ldots
$$

So, for $u \in F(S) \cap \operatorname{VI}(C, A)$, we have

$$
\begin{aligned}
0 & \leq\left\langle x_{0}-x_{n}, x_{n}-u\right\rangle \\
& =\left\langle x_{0}-x_{n}, x_{n}-x_{0}+x_{0}-u\right\rangle \\
& =-\left\|x_{0}-x_{n}\right\|^{2}+\left\|x_{0}-x_{n}\right\|\left\|x_{0}-u\right\| .
\end{aligned}
$$

This implies that

$$
\left\|x_{0}-x_{n}\right\| \leq\left\|x_{0}-u\right\| \text { for all } u \in F(S) \cap \operatorname{VI}(C, A) \text { and } n=1,2,3 \ldots
$$

By the same as in the proof of [15, Theorem 3.3], we can show that $\left\langle x_{0}-x_{n}, x_{n}-x_{n+1}\right\rangle \geq 0$ and hence $\lim _{n \rightarrow \infty}\left\|x_{n+1}-x_{n}\right\|=0$.

On the other hand, from $x_{n+1} \in C_{n+1} \subset C$, we have

$$
\left\|z_{n}-x_{n+1}\right\| \leq\left\|x_{n}-x_{n+1}\right\| \text {. }
$$

Further, we have

$$
\begin{aligned}
\left\|z_{n}-x_{n}\right\| & =\left\|\alpha_{n} x_{n}+\left(1-\alpha_{n}\right) S_{n} v_{n}-x_{n}\right\| \\
& =\left(1-\alpha_{n}\right)\left\|S_{n} v_{n}-x_{n}\right\| .
\end{aligned}
$$

As in the proof of Theorem 3.1 (Step 3), we obtain

$$
\lim _{n \rightarrow \infty}\left\|x_{n}-S_{n} v_{n}\right\|=0 \text { and } \lim _{n \rightarrow \infty}\left\|x_{n}-S x_{n}\right\|=0
$$

since $\left\{x_{n}\right\}$ is bounded. Let $\left\{x_{n_{i}}\right\}$ be a subsequence of $\left\{x_{n}\right\}$ such that $x_{n_{i}} \rightarrow z_{0}$. By the same argument as in the proof of [6, Theorem 3.1, pp. 346-347], we can show that $z_{0} \in \operatorname{VI}(C, A)$. Since $I-S$ is demiclosed, it follows by Lemma 2.1 that $z_{0} \in F(S)$. Hence $z_{0} \in F(S) \cap \operatorname{VI}(C, A)$.

Finally, we show that $x_{n} \rightarrow w$, where $w=P_{F(S) \cap \mathrm{VI}(C, A)} x_{0}$. Since $\left\{x_{n}\right\}$ is bounded, there exists a subsequence $\left\{x_{n_{k}}\right\}$ of $\left\{x_{n}\right\}$ such that $x_{n_{k}} \rightarrow w^{\prime}$. Since $\left\{x_{n_{k}}\right\} \subset C$ and $C$ is closed and convex, we obtain $w^{\prime} \in C$.

Since $x_{n}=P_{C_{n}} x_{0}$ and $w \in F(S) \cap \operatorname{VI}(C, A) \subset C_{n}$, we have

$$
\left\|x_{n}-x_{0}\right\| \leq\left\|w-x_{0}\right\|
$$

It follows from $w=P_{F(S) \cap \mathrm{VI}(C, A)} x_{0}$ and the lower semicontinuity of the norm that

$$
\left\|w-x_{0}\right\| \leq\left\|w^{\prime}-x_{0}\right\| \leq \liminf _{k \rightarrow \infty}\left\|x_{n_{k}}-x_{0}\right\| \leq \limsup _{k \rightarrow \infty}\left\|x_{n_{k}}-x_{0}\right\| \leq\left\|w-x_{0}\right\| .
$$

Thus, we obtain that $\lim _{k \rightarrow \infty}\left\|x_{n_{k}}-x_{0}\right\|=\left\|w^{\prime}-x_{0}\right\|=\left\|w-x_{0}\right\|$. Using the Kadec-Klee property of $H$, we obtain that

$$
\lim _{k \rightarrow \infty} x_{n_{k}}=w^{\prime}=w .
$$

Therefore $\left\{x_{n}\right\}$ converges strongly to $w$, where $w=P_{F(T) \cap \mathrm{VI}(C, A)} x_{0}$.

Setting $S_{n} \equiv S$ in Theorem 3.4, we have the following result.

THEOREM 3.5. Let $C$ be a nonempty closed convex subset of a real Hilbert space H. Let $A$ be a monotone and $k$-Lipschitz-continous mapping of $C$ into $H$. Let $S$ be a nonexpansive 
mappings from $C$ into itself such that $F(S) \cap \operatorname{VI}(C, A) \neq \emptyset$ and let $x_{0} \in H$. For $C_{1}=C$ and $x_{1}=P_{C_{1}} x_{0}$, define a sequence $\left\{x_{n}\right\}$ of $C$ as follows:

$$
\begin{aligned}
y_{n} & =P_{C}\left(x_{n}-\lambda_{n} A x_{n}\right), \\
z_{n} & =\alpha_{n} x_{n}+\left(1-\alpha_{n}\right) S P_{C}\left(x_{n}-\lambda_{n} A y_{n}\right), \\
C_{n+1} & =\left\{z \in C_{n}:\left\|z_{n}-z\right\| \leq\left\|x_{n}-z\right\|\right\}, \\
x_{n+1} & =P_{C_{n+1}} x_{0}, \quad n=1,2,3 \ldots,
\end{aligned}
$$

where $0 \leq \alpha_{n}<c<1$ and $0<a<\lambda_{n}<b<2 \alpha$ for all $n=1,2,3 \ldots$ Then $\left\{x_{n}\right\}$ converges strongly to $z_{0}=P_{F(S) \cap \mathrm{VI}(C, A)} x_{0}$.

Setting $P_{C}\left(I-\lambda_{n} A\right)=I$ in Theorem 3.4, we obtain Theorem 1.2.

\section{Applications}

4.1. Monotone operator. In this section, we consider the problem of finding a zero of a monotone operator. A multivalued operator $T: H \rightarrow 2^{H}$ with domain $D(T)=\{z \in$ $H: T z \neq \emptyset\}$ and range $R(T)=\{T z: z \in D(T)\}$ is said to be monotone if for each $x_{i} \in D(T)$ and $y_{i} \in T x_{i}, i=1,2$, we have $\left\langle x_{1}-x_{2}, y_{1}-y_{2}\right\rangle \geq 0$. A monotone operator $T$ is said to be maximal if its graph $G(T)=\{(x, y): y \in T x\}$ is not properly contained in the graph of any other monotone operator. Let $I$ denote the identity operator on $H$ and let $T: H \rightarrow 2^{H}$ be a maximal monotone operator. Then we can define, for each $r>0$, a nonexpansive single valued mapping $J_{r}: H \rightarrow H$ by $J_{r}=(I+r T)^{-1}$. It is called the resolvent (or the proximal mapping) of $T$. We also define the Yosida approximation $A_{r}$ by $A_{r}=\left(I-J_{r}\right) / r$. We know that $A_{r} x \in T J_{r} x$ and $\left\|A_{r} x\right\| \leq \inf \{\|y\|: y \in T x\}$ for all $x \in H$. We also know that $T^{-1} 0=F\left(J_{r}\right)$ for all $r>0$; see, for instance, Rockafellar [14].

Lemma 4.1 (the resolvent identity). For $\lambda, \mu>0$, there holds the identity

$$
J_{\lambda} x=J_{\mu}\left(\frac{\mu}{\lambda}+\left(1-\frac{\mu}{\lambda}\right) J_{\lambda} x\right), \quad x \in H .
$$

By using Theorem 3.1 and Lemma 4.1 we may obtain the following improvement.

LEMma 4.2. Let $C$ be a nonempty closed convex subset of a real Hilbert space $H$. Let $T \subset H \times H$ be a maximal monotone operator such that $\overline{D(T)} \subset C \subset \bigcap_{r>0} R(I+r T)$ and let $J_{r}$ be the resolvent of $T$ and $\left\{r_{n}\right\}$ be a sequence in $(0, \infty)$. If $\inf \left\{r_{n}: n=1,2,3 \ldots\right\}>0$, and $\sum_{n=1}^{\infty}\left|r_{n+1}-r_{n}\right|<\infty$, then

(i) $\sum_{n=1}^{\infty} \sup \left\{\left\|J_{r_{n+1}} z-J_{r_{n}} z\right\|: z \in B\right\}<\infty$ for any bounded subset $B$ of $H$,

(ii) $J_{r} x=\lim _{n \rightarrow \infty} J_{r_{n}} x$ for all $x \in C$ and $F\left(J_{r}\right)=\bigcap_{n=1}^{\infty} F\left(J_{r_{n}}\right)$, where $\lim _{n \rightarrow \infty} r_{n}=r$.

Proof. We first prove (i). Let $B$ be a bounded subset of $H$. Since $\left\{J_{r_{n}} z: z \in B, n=\right.$ $1,2,3 \ldots\}$ is bounded, from Lemma 4.1, using the resolvent identity

we obtain

$$
J_{r_{n+1}} z=J_{r_{n}}\left(\frac{r_{n}}{r_{n+1}} z+\left(1-\frac{r_{n}}{r_{n+1}}\right) J_{r_{n+1}} z\right), \quad z \in H,
$$

$$
\begin{aligned}
\left\|J_{r_{n+1}} z-J_{r_{n}} z\right\| & \leq \frac{\left|r_{n+1}-r_{n}\right|}{r_{n+1}}\left\|J_{r_{n+1}} z-z\right\| \\
& \leq M\left|r_{n+1}-r_{n}\right|
\end{aligned}
$$


for each $z \in B$ and $n=1,2,3 \ldots$ where $M=\frac{\sup \left\{\left\|J_{r_{n+1}} z-z\right\|: z \in B, n=1,2,3 \ldots\right\}}{\inf \left\{r_{n}: n=1,2,3 \ldots\right\}}$. Hence we get

$$
\sum_{n=1}^{\infty} \sup \left\{\left\|J_{r_{n+1}} z-J_{r_{n}} z\right\|: z \in B\right\} \leq M \sum_{n=1}^{\infty}\left|r_{n+1}-r_{n}\right|<\infty .
$$

Next, we prove (ii). By the assumption for $\left\{r_{n}\right\}$, we know that $r_{n} \rightarrow r$ for some $r>0$. Since $\left\|J_{r} z-J_{r_{n}} z\right\| \leq \frac{\left|r-r_{n}\right|}{r}\left\|z-J_{r} z\right\|$, we obtain that $\lim _{n \rightarrow \infty} J_{r_{n}} z=J_{r} z$ for all $z \in H$. Then $J_{r} x=\lim _{n \rightarrow \infty} J_{r_{n}} x$ for all $x \in C$ and hence $F\left(J_{r}\right)=\bigcap_{n=1}^{\infty} F\left(J_{r_{n}}\right)=T^{-1} 0$.

By Lemmas 4.2 and Theorem 3.1, we have the following theorem.

THEOREM 4.3. Let $C$ be a nonempty closed convex subset of a real Hilbert space $H$. Let $T \subset H \times H$ be a maximal monotone operator such that $T^{-1} 0 \neq \emptyset$ and $\overline{D(T)} \subset$ $C \subset \bigcap_{r>0} R(I+r T)$ and let $J_{r}$ be the resolvent of $T$. Let $\alpha>0$ and let $A$ be an $\alpha$-inverse-strongly monotone mapping of $C$ into $H$. Let $\left\{x_{n}\right\}$ be a sequence in $C$ defined as follows:

$$
\begin{aligned}
x_{0} & \in C \quad \text { is arbitrary, } \\
y_{n} & =\alpha_{n} x_{n}+\left(1-\alpha_{n}\right) J_{r_{n}}\left(x_{n}-\lambda_{n} A\left(x_{n}-\lambda_{n} A x_{n}\right)\right), \\
C_{n} & =\left\{z \in C:\left\|y_{n}-z\right\| \leq\left\|x_{n}-z\right\|\right\}, \\
Q_{n} & =\left\{z \in C:\left\langle x_{n}-z, x_{0}-x_{n}\right\rangle \geq 0\right\}, \\
x_{n+1} & =P_{C_{n} \cap Q_{n}} x_{0}, \quad n=0,1,2, \ldots,
\end{aligned}
$$

where $0 \leq \alpha_{n}<a<1$ for all $n=1,2,3 \ldots,\left\{\lambda_{n}\right\} \subset(a, b) \subset(0,2 \alpha)$ and $\left\{r_{n}\right\}$ is a sequence in $(0, \infty)$. If $\inf \left\{r_{n}: n=1,2,3 \ldots\right\}>0$ and $\sum_{n=1}^{\infty}\left|r_{n+1}-r_{n}\right|<\infty$, then $\left\{x_{n}\right\}$ converges strongly to $z$, where $z=P_{T^{-1} 0 \cap \mathrm{VI}(C, A)} x_{0}$.

Proof. Since $H$ is a Hilbert space, $C=\overline{D(T)}$ is closed and convex and $F\left(J_{r}\right)=T^{-1} 0$ for all $r>0$. By Lemma 4.2, we have the following

$$
F\left(J_{r} x\right)=\bigcap_{n=1}^{\infty} F\left(J_{r_{n}}\right)=T^{-1} 0 \neq \emptyset .
$$

We note that $F(T)=\operatorname{VI}(A, C)$. Therefore, by Theorem 3.1, we obtain $\left\{x_{n}\right\}$ converges strongly to $z=P_{T^{-1} 0 \cap \mathrm{VI}(C, A)} x_{0}$.

4.2. Strictly pseudocontractive mappings. A mapping $T: C \rightarrow C$ is called strictly pseudocontractive on $C$ if there exists $k$ with $0 \leq k<1$ such that

$$
\|T x-T y\|^{2} \leq\|x-y\|^{2}+k\|(I-T) x+(I-T) y\|^{2}, \text { for all } x, y \in C .
$$

If $k=0$, then $T$ is nonexpansive. Put $A=I-T$, where $T: C \rightarrow C$ is a strictly pseudocontractive mapping with $k$. We know that $A$ is $\frac{1-k}{2}$-inverse strongly monotone and $A^{-1} 0=F(T)$ (see [6] and [19]).

Using Theorem 3.1, we have the following theorem.

THEOREM 4.4. Let $C$ be a nonempty closed convex subset of a real Hilbert space $H$. Let $\left\{S_{n}\right\}$ be a sequence of nonexpansive mappings from $C$ into itself. Let $T$ be a strictly pseudocontractive mapping with constant $k$ of $C$ into itself and let $\left\{x_{n}\right\}$ be a sequence 
generated by

$$
\begin{aligned}
x_{0} & \in C \text { is arbitrary, } \\
y_{n} & =\alpha_{n} x_{n}+\left(1-\alpha_{n}\right) S_{n} P_{C}\left(\left(1-\lambda_{n}\right) x_{n}+\lambda_{n} T\left(x_{n}-\lambda_{n} A x_{n}\right)\right), \\
C_{n} & =\left\{z \in C:\left\|y_{n}-z\right\| \leq\left\|x_{n}-z\right\|\right\}, \\
Q_{n} & =\left\{z \in C:\left\langle x_{n}-z, x_{0}-x_{n}\right\rangle \geq 0\right\}, \\
x_{n+1} & =P_{C_{n} \cap Q_{n}} x_{0}, \quad n=0,1,2 \ldots,
\end{aligned}
$$

where $0 \leq \alpha_{n}<a<1$ for all $n=1,2,3 \ldots$ and $\left\{\lambda_{n}\right\} \subset(a, b) \subset(0,2 \alpha)$.

Let $\sum_{n=1}^{\infty} \sup \left\{\left\|S_{n+1} z-S_{n} z\right\|: z \in B\right\}<\infty$ for any bounded subset $B$ of $C$ and $S$ be a mapping of $C$ into itself defined by $S z=\lim _{n \rightarrow \infty} S_{n} z$ for all $z \in C$ and suppose that $F(S)=\bigcap_{n=1}^{\infty} F\left(S_{n}\right)$. Then $\left\{x_{n}\right\}$ converges strongly to $P_{F(S) \cap F(T)} x_{0}$.

Proof. Put $A=I-T$. Then $A$ is $\frac{1-k}{2}$-inverse-strongly monotone. We have that $F(T)$ is the solution set of $\operatorname{VI}(A, C)$ i.e., $F(T)=\mathrm{VI}(A, C)$ and

$$
P_{C}\left(x_{n}-\lambda_{n} A\left(x_{n}-\lambda_{n} A x_{n}\right)\right)=\left(1-\lambda_{n}\right) x_{n}+\lambda_{n} T\left(x_{n}-\lambda_{n} A x_{n}\right) .
$$

Therefore, by Theorem 3.2, $\left\{x_{n}\right\}$ converges strongly to $z=P_{F(S) \cap F(T)} x_{0}$.

Acknowledgments. The authors would like to thank the Thailand Research Fund and the Commission on Higher Education under Grant No. MRG5380044 for their financial support.

\section{References}

[1] K. Aoyama, Y. Kimura, W. Takahashi, M. Toyoda, Approximation of common fixed points of a countable family of nonexpansive mappings in a Banach space, Nonlinear Anal. 67 (2007), 2350-2360.

[2] F. E. Browder, Nonlinear operators and nonlinear equations of evolution in Banach spaces, Proc. Symp. Pure Math. 18 (1976), 78-81.

[3] K. Goebel, W. A. Kirk, Topics in Metric Fixed Point Theory, Cambridge Univ. Press, Cambridge, 1990.

[4] E. G. Gol'shteĭn, N. V. Tret'yakov, Modified Lagrangians in convex programming and their generalizations, Math. Programming Stud. 10 (1979), 86-97.

[5] Y. Haugazeau, Sur les inéquations variationnelles et la minimisation de fonctionnelles convexes, Ph. D. Thèse, Université de Paris, Paris, France, 1968.

[6] H. Iiduka, W. Takahashi, Strong convergence theorems for nonexpansive mapping and inverse-strongly monotone mappings, Nonlinear Anal. 61 (2005), 341-350.

[7] H. Iiduka, W. Takahashi, M. Toyoda, Approximation of solutions of variational inequalities for monotone mappings, Panamer. Math. J. 14 (2004), 49-61.

[8] G. M. Korpelevich, An extragradient method for finding saddle points and for other problems, Ékonom. i Mat. Metody 12 (1976), 747-756.

[9] W. R. Mann, Mean value methods in iteration, Proc. Amer. Math. Soc. 4 (1953), 506-510.

[10] N. Nadezhkina, W. Takahashi, Strong convergence theorem by a hybrid method for nonexpansive mappings and Lipschitz-continuous monotone mappings, SIAM J. Optim. 16 (2006), 1230-1241. 
[11] N. Nadezhkina, W. Takahashi, Weak convergence theorem by an extragradient method for nonexpansive mappings and monotone mappings, J. Optim. Theory Appl. 128 (2006), 191-201.

[12] K. Nakajo, W. Takahashi, Strong convergence theorems for nonexpansive mappings and nonexpansive semigroups, J. Math. Anal. Appl. 279 (2003), 372-379.

[13] Z. Opial, Weak convergence of the sequence of successive approximations for nonexpansive mappings, Bull. Amer. Math. Soc. 73 (1967), 591-597.

[14] R. T. Rockafellar, Monotone operators and the proximal point algorithm, SIAM J. Control Optim. 14 (1976), 877-898.

[15] W. Takahashi, Y. Takeuchi, R. Kubota, Strong convergence theorems by hybrid methods for families of nonexpansive mappings in Hilbert spaces, J. Math. Anal. Appl. 341 (2008), 276-286.

[16] W. Takahashi, M. Toyoda, Weak convergence theorems for nonexpansive mappings and monotone mappings, J. Optim. Theory Appl. 118 (2003), 417-428.

[17] J.-C. Yao, O. Chadli, Pseudomonotone complementarity problems and variational inequalities, in: Handbook of Generalized Convexity and Generalized Monotonicity, Springer, New York, 2005, 501-558.

[18] L. C. Zeng, S. Schaible, J. C. Yao, Iterative algorithm for generalized set-valued strongly nonlinear mixed variational-like inequalities, J. Optim. Theory Appl. 124 (2005), 725-738.

[19] L. C. Zeng, N. C. Wong, J. C. Yao, Strong convergence theorems for strictly pseudocontractive mappings of Browder-Petryshyn type, Taiwanese J. Math. 10 (2006), 837-850.

[20] L. C. Zeng, J. C. Yao, Strong convergence theorem by an extragradient method for fixed point problems and variational inequality problems, Taiwanese J. Math. 10 (2006), 12931303. 
